\title{
Management of hyperglycaemia in type 2 diabetes: \\ a consensus algorithm for the initiation and adjustment of therapy
}

\section{A consensus statement from the American Diabetes Association and the European Association for the Study of Diabetes}

\section{M. Nathan • J. B. Buse • M. B. Davidson •}

R. J. Heine • R. R. Holman • R. Sherwin • B. Zinman

Published online: 13 September 2006

(C) Springer-Verlag 2006

The online version of the original article can be found at http://dx.doi. org/10.1007/s00125-006-0316-2.

D. M. Nathan $(\bowtie)$

Diabetes Center,

Massachusetts General Hospital and Harvard Medical School,

Boston, MA, USA

e-mail: dnathan@partners.org

J. B. Buse

University of North Carolina School of Medicine,

Chapel Hill, NC, USA

\section{B. Davidson}

Clinical Trials Unit, Charles R. Drew University,

Los Angeles, CA, USA

R. J. Heine

Diabetes Center, VU University Medical Center,

Amsterdam, The Netherlands

R. R. Holman

Diabetes Trials Unit, Oxford Centre for Diabetes,

Endocrinology and Metabolism, Oxford University,

Oxford, UK

\section{R. Sherwin}

Department of Internal Medicine and Endocrinology,

Yale University School of Medicine,

New Haven, CT, USA

\section{B. Zinman}

Departments of Endocrinology and Metabolism,

Mount Sinai Hospital, University of Toronto,

Toronto, ON, Canada
In Fig. 1, a '>' symbol was mistakenly used in place of a '<' symbol. In Fig. 2, an arrow was incorrectly positioned.

The corrected figures are reproduced here with the amendments shown in red. 
Fig. 1 Initiation and adjustment of insulin regimens. Insulin regimens should be designed taking lifestyle and meal schedule into account. The algorithm can only provide basic guidelines for initiation and adjustment of insulin. See [71] for more detailed instructions. ${ }^{\text {a Premixed insulins }}$ are not recommended during adjustment of doses; however, they can be used conveniently, usually before breakfast and/or dinner if the proportion of rapidand intermediate-acting insulins is similar to the fixed proportions available. $b g$ Blood glucose

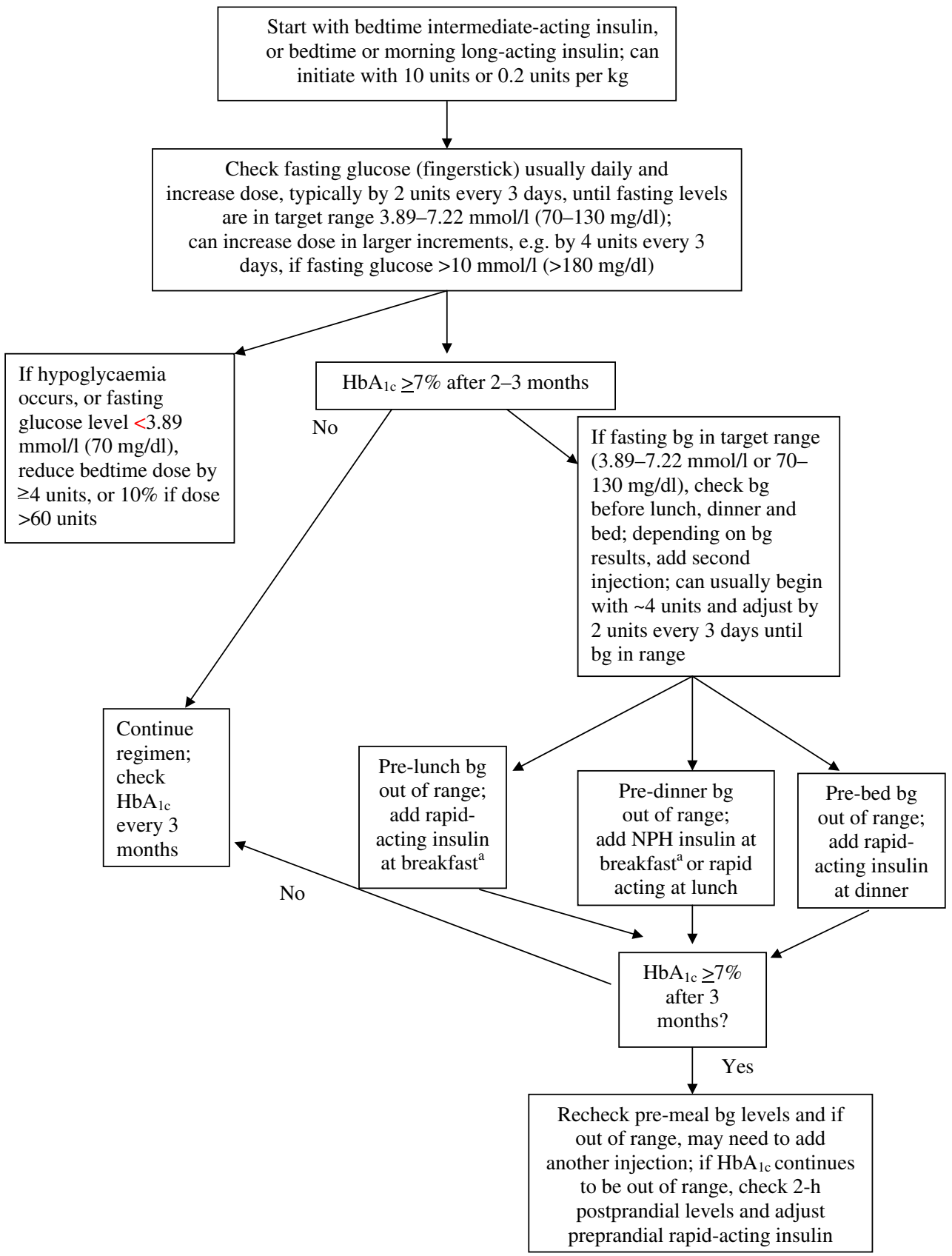


Fig. 2 Algorithm for the metabolic management of type 2 diabetes. Reinforce lifestyle intervention at every visit. a Check $\mathrm{HbA}_{1 \mathrm{c}}$ every 3 months until $\mathrm{HbA}_{1 \mathrm{c}}$ is $<7 \%$, and then at least every 6 months. b Although three oral agents can be used, initiation and intensification of insulin therapy is preferred based on effectiveness and expense.

c See Fig. 1 for initiation and adjustment of insulin

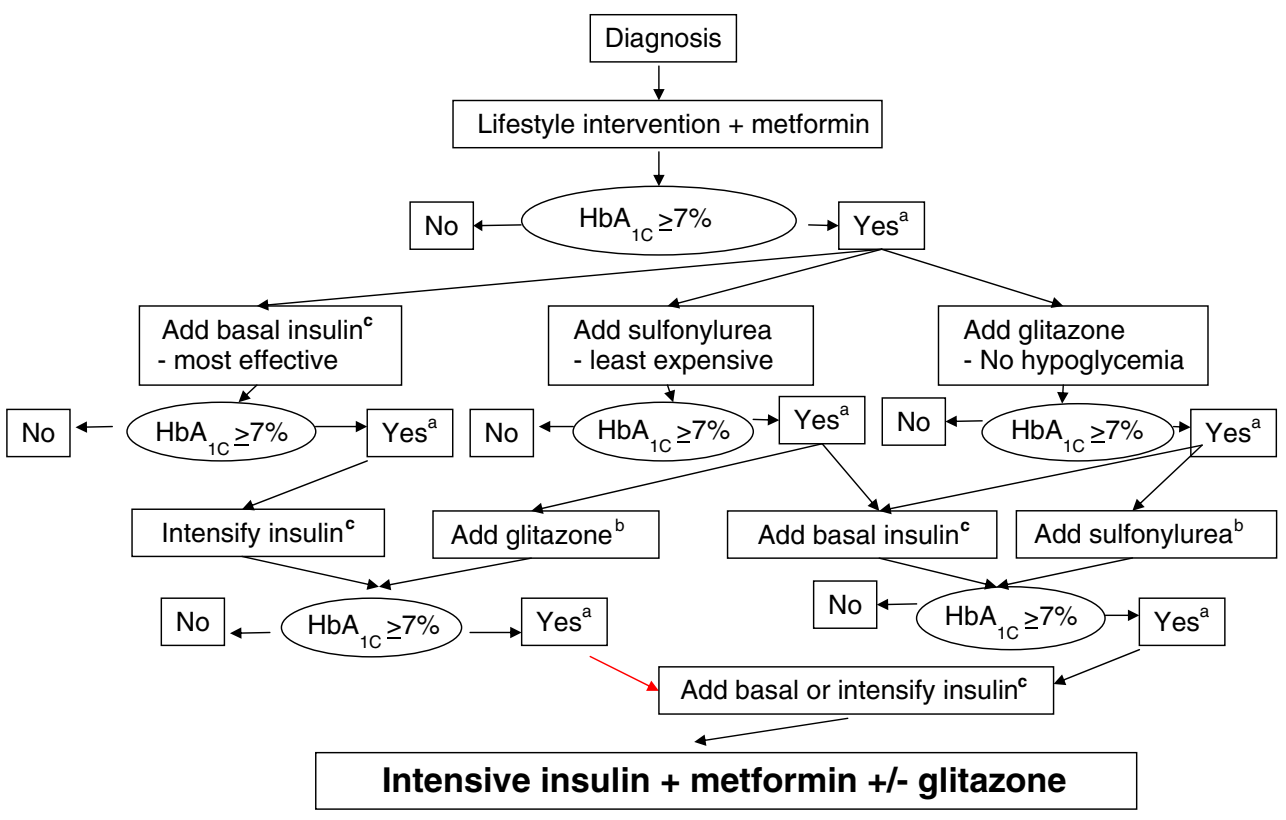

